\title{
BMJ Open Emigration of regional quota graduates of Japanese medical schools to non- designated prefectures: a prospective nationwide cohort study
}

\author{
Shuhei Yoshida, ${ }^{1}$ Masatoshi Matsumoto, ${ }^{1}$ Saori Kashima, ${ }^{2}$ Tetsuhiro Owaki, ${ }^{3}$ \\ Seitaro Iguchi, ${ }^{4}$ Kazuo Inoue, ${ }^{5}$ Susumu Tazuma, ${ }^{6}$ Takahiro Maeda $^{7}$
}

To cite: Yoshida S, Matsumoto M, Kashima S, et al. Emigration of regional quota graduates of Japanese medical schools to nondesignated prefectures: a prospective nationwide cohort study. BMJ Open 2019;9:e029335. doi:10.1136/ bmjopen-2019-029335

- Prepublication history for this paper is available online. To view these files, please visit the journal online (http://dx.doi org/10.1136/bmjopen-2018029335).

Received 22 January 2019 Revised 12 June 2019 Accepted 2 July 2019

D Check for updates

(c) Author(s) (or their employer(s)) 2019. Re-use permitted under CC BY-NC. No commercial re-use. See rights and permissions. Published by BMJ.

For numbered affiliations see end of article.

\section{Correspondence to}

Dr Shuhei Yoshida;

yoshida.shuhei.0810@gmail. com

\section{ABSTRACT}

Objectives This study examined the retention of regional quota graduates of Japanese medical schools and prefecture scholarship recipients within their designated prefectures where they are obliged or expected to work and revealed the personal and regional characteristics associated with their emigration to nondesignated prefectures. Regional quota and prefecture scholarship are two of the most ambitious policies ever conducted in Japan for recruiting physicians to practice in rural areas.

Design Prospective cohort study.

Setting Nationwide.

Participants Regional quota graduates with prefecture scholarship, quota graduates without scholarship and nonquota graduates with scholarship of Japanese medical schools who obtained their physician license between 2014 and 2016.

Primary outcome The emigration in 2016 of the participants from the designated prefectures.

Results Total participants were 991 physicians, three of whom were excluded due to the missing values of crucial items, leaving 988 participants for analysis (quota with scholarship 387, quota alone 358 and scholarship alone 243). The percentage of those who emigrated was $11.9 \%$ $(118 / 988)$. The mean $( \pm S D)$ proportion of subjects who emigrated was $11.7 \%( \pm 10.3)$ among all prefectures and the proportion varies widely among prefectures $(0 \%$ 44.4\%). Multilevel logistic regression analysis showed those who received prefecture scholarship (OR 0.23; 95\% $\mathrm{Cl} 0.08$ to 0.67 ) and whose designated prefecture has an ordinance-designated city (ie, large city) were less likely to emigrate (OR $0.47 ; 95 \% \mathrm{Cl} 0.24$ to 0.90 ). In contrast, graduates from a medical school outside the designated prefecture (OR 4.20; $95 \% \mathrm{Cl} 2.20$ to 7.67$)$ and who have a right to postpone their obligatory service (OR 3.42; $95 \% \mathrm{Cl}$ 1.52 to 7.67 ) were more likely to emigrate.

Conclusions A substantial proportion of regional quota graduates and prefecture scholarship recipients emigrated to non-designated prefectures. Emigrations should be reduced by improving the potential facilitators for emigration such as discordance in location between medical school and designated prefecture.

\section{Strengths and limitations of this study}

- This is the first nationwide cohort study to follow up with physicians from regional quota admission programmes of medical schools and prefecture scholarship programmes, which are among the largest national policies enacted to improve Japan's geographically uneven distribution of physicians.

- With the support of concerned ministries and the representative body of medical schools, subjects from most of Japan's prefectural governments and medical schools were recruited.

- Based on the prospective design, a strong causal relationship was assumed between the migration of the study subjects from one designated prefecture to another and their personal/geographic backgrounds.

- Increasing the recruitment rate of participants, prolonging the observation period and focusing on emigration with contract dissolution are challenges to be tackled in the future studies.

\section{INTRODUCTION}

Uneven geographic distribution of physicians in Japan

The lopsided geographical distribution of physicians is a chronic social problem in many countries. ${ }^{12}$ Approximately one half of the population lived in rural areas, but less than $25 \%$ of the physicians worked in rural area. ${ }^{3}$ In response to this problem, the WHO recommends that medical schools increase the proportion of medical students from a rural background. ${ }^{3}$ Another recommendation is to promote primary care education for medical students in rural areas. ${ }^{3}$ In the USA, there are pipeline courses of medical schools which have a preference for students with rural origin and encourage them to become family physicians. These courses have been successful in retaining physicians in rural areas. ${ }^{4}$ There are rural clinical schools across Australia and the education for primary care 
in rural areas is a national policy. ${ }^{5}$ Many other countries have systems to allocate physicians, as a mandatory service, to rural areas. ${ }^{6}$

Since the early 20th century, the dearth of doctors in rural parts of Japan has demanded a political solution. ${ }^{78}$ Despite numerous initiatives and policies such as 1-ken-1-idai-seisaku-one medical school in each prefecture-in the 1970s and 1980s, and Jichi Medical University, founded in 1972 and dedicated to producing rural physicians, ${ }^{8}$ the problem has persisted. ${ }^{79}$ The overconcentration of physicians in cities at the expense of rural areas has even worsened since 2004 when the nationwide new residency training programme for postgraduate year 1 and year 2 physicians was implemented..$^{11}$

\section{Regional quota of medical schools and prefecture scholarship programme}

To counter the worsening shortage of doctors in rural areas, the national government, in cooperation with prefecture governments and medical schools, adopted a chiikiwaku: a regional quota programme at medical schools in $2008 .^{12}$ The quota is a special admission quota recruiting local high school graduates and training them to be physicians in their community. Although each medical school's regional quota is different in size and design, most quotas have at least one (often all) of the following elements: (1) applicants must have a geographic background either in the prefecture in which the medical school is located or in the prefecture in which they are obliged or expected to work; (2) they are selected through a special admission process; (3) their undergraduate medical education introduces them to rural practice and (4) graduates are obliged or expected to work in the prefecture for a designated period of years in rural areas. ${ }^{13} 14$ The prefecture government offers scholarships to more than half of the regional quota entrants for at least part of their 6years of undergraduate medical education. In exchange, they must work in the designated prefecture for about 1.5 times the length of the scholarship term; customarily one-third to one-half of the obligatory period is to be spent practicing in the prefecture's rural municipalities. ${ }^{14}$ In all quotas with scholarship, the graduates do not need to pay back the scholarship they received by completing the obligatory service.

As part of the quota is separate from the prefecture scholarship, graduates of such a quota are not required, but expected to work in the prefecture. Aside from the scholarship bundled with the regional quotas, many prefectures have their own scholarships that are available to students who entered medical schools through the usual admission process and hope to practice in the prefecture. The amount of the scholarship is usually the same as that offered to quota students with scholarship, as are the length and obligatory service requirement. ${ }^{12} 14$ Because the regional quota has started only recently, graduates of regional quota have been working as physicians for 5 years or less.
The quota had spread to about $90 \%$ of the Japanese medical schools by the end of 2017. The number of entrants to the quota is 1521 in 2017 or $16 \%$ of all enrolled medical students nationwide. The regional quota is one of the largest and most ambitious policies ever conducted in Japan to redress the unequal distribution of physicians. ${ }^{13}$

\section{Reported outcomes of regional quota and scholarship}

Several outcomes of Japanese regional quota and prefecture scholarship programmes have been reported. A higher proportion of regional quota graduates and scholarship recipients than of non-quota and non-scholarship physicians worked in rural areas,. ${ }^{15}$ The regional quota graduates and scholarship recipients had a higher pass rate of the National License Examination for Physicians than the other graduates. ${ }^{12}$ The percentage of quota graduates with scholarship who remained in the scholarship contract, that is, who did not buy out the scholarship contract, 3 years after graduation was $92.2 \%$; the comparable percentage for non-quota graduates with scholarship was $89.9 \%{ }^{12}$

\section{Emigration of the graduates from the designated prefecture}

Because the purpose of the quota and scholarship programmes is to recruit physicians who will practice in designated prefectures, emigration of the quota graduates and scholarship recipients from designated to non-designated prefectures is not a desirable outcome. In fact it is being a grave social problem in Japan as the number of graduates of regional quota is expanding rapidly. ${ }^{16}$ Since many prefectures permit such emigration by recognising it as postponement of the obligatory service, this emigration is not necessarily considered a breach of obligation. However, a substantial proportion of those who do breach the obligation by buying out the scholarship are supposed to emigrate from the designated prefectures. The cases of emigration thus presumably include a substantial number of buy-outs. Whether or not the emigration accompanies buy-out, emigration itself is outside the purpose of these programmes and is therefore undesirable. Past evidence has shown that practice location in the early stage of a physician's career substantially influence their later choice of location. ${ }^{17}{ }^{18}$ For this reason, too, early-career physicians should be discouraged from emigrating. However, the scientific literature has not reported on the current status of emigration among regional quota graduates and scholarship recipients.

\section{Study aim}

This study evaluates the emigration status of regional quota graduates and scholarship recipients. We also show which personal and geographic characteristics are associated with their emigration. These results will serve as the scientific evidence for evaluating the regional quota system in medical schools and redesigning it to be more effective and sustainable. 


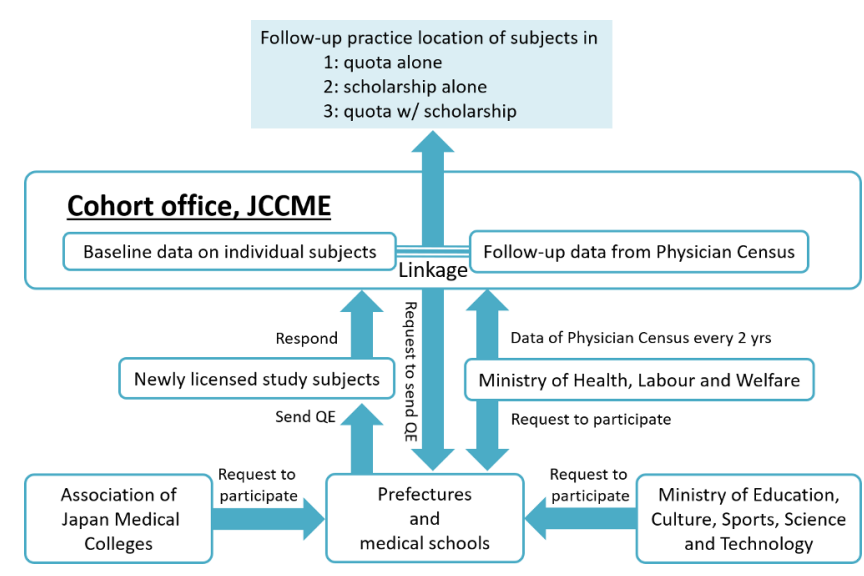

Figure 1 Study design. A part of this figure was reported previously. ${ }^{14}$ JCCME, Japanese Council for Communitybased Medical Education; QE, questionnaire.

\section{METHODS}

\section{Medical education system in Japan}

In Japan, high school graduates must pass a competitive entrance examination for admission to a medical school. Medical schools have not traditionally restricted the geographic background of their applicants, so all medical schools, even in rural areas, attract applicants from all over Japan. Candidates for the regional quota, however, tend to be graduates from the local high school who hope to become practicing physicians within the prefecture. After finishing 6 years of medical school education and passing the National License Examination for Physicians, graduates begin their 2 years of initial clinical training as resident physicians.

\section{Baseline surveys}

This study is a part of the nationwide prospective cohort study conducted by the Japanese Council for Community-based Medical Education (JCCME). ${ }^{14}$ The participants in the study had entered a medical school as chiikiwaku: a regional quota and/or a recipient of a prefecture scholarship. The design for the cohort study is illustrated in figure $1 .^{14}$

Potential subjects were all the regional quota and/or scholarship physicians who graduated from a medical school and licensed in 2014-2016. The details of this study protocol have been previously reported. ${ }^{12} 1415$

Every November since 2013, all 47 prefectures and 77 medical schools except for Jichi Medical University, National Defence Medical College and the University of Occupational and Environmental Health completed a presurvey questionnaire, sent from the cohort study office of JCCME, asking how many eligible subjects were in each prefecture or school.

The main survey, based on the presurvey results, has been administered each June since 2014. The cohort office asked each prefecture and medical school to forward a questionnaire to all prospective study participants. The prefecture then sent the questionnaire to all quota and non-quota graduates with scholarship; the medical school sent the questionnaire to all of its quota graduates without scholarship. Each participant then returned the completed questionnaire to the cohort office, which was registered as the baseline data at the office. The questionnaire for each participant in the group of quota with scholarship and that of scholarship alone asks whether the participant was admitted to a quota, physician identification number, name of the medical school, year of graduation, home prefecture, length of funded period, term of scholarship, length of postgraduate obligation period and length of rural service. The questionnaire for each participant in the group of quota without scholarship requests the participant's physician identification number, medical school, graduation year, home prefecture and conditions for admission to the quota. All subjects were newly licensed physicians. The Ministry of Health, Labour and Welfare, the Ministry of Education Culture, Sports, Science and Technology and the Association of Japan Medical Colleges supported this study by requesting the participation of prefectures and/or medical schools. ${ }^{14}$

\section{Follow-up of individual participants}

The baseline individual data were connected, through physician identification number, to the national 'Survey of Physicians, Dentists and Pharmacists 2016' (Physician Census). The Ministry of Health conducts the biennial Physician Census in December. Under Japanese law, all licensed physicians must register in the Physician Census which includes information on practice location, type of medical facility, work contents, specialty and board certification status. In 2017, the cohort office asked the Ministry of Health for non-published individualised data of Physician Census 2016. In 2018, the Ministry forwarded the data to the office with special permission to use the data for the research (permission no. 0411-3).

Among the 319481 physicians registered in the Census, 23897 who were licensed in 2014-2016 were extracted. Data on the 23897 physicians were connected, through the physician identification number, to the baseline data. By connecting the baseline and the Census data, it was possible to identify the location in which the study subjects and their counterparts (physicians with the same career length) practiced.

\section{Municipality data}

Japan has municipal, prefectural and national levels of government. Municipal (city, town, village) data on populations and land areas in 2015, the year closest to the Physician Census, were extracted from the National Population Census compiled by the Statistics Bureau, Ministry of Internal Affairs and Communications. ${ }^{12}$ The physician data were connected to this municipality-based population data through the municipality code. 
Table 1 Participants' characteristics

\begin{tabular}{|c|c|c|c|}
\hline & Quota w/scholarship & Scholarship alone & Quota alone \\
\hline & $\mathrm{n}=387(39.2 \%)$ & $\mathrm{n}=358(36.2 \%)$ & $n=243(24.6 \%)$ \\
\hline \multicolumn{4}{|l|}{ Baseline } \\
\hline Female, no. (\%) & $172(44.4)$ & $115(32.1)$ & $117(48.1)$ \\
\hline Graduation from a private medical school, no. (\%) & $37(9.6)$ & $49(13.7)$ & $30(12.4)$ \\
\hline Years of duty period, mean (SD), years & $7.7(2.7)$ & $6.1(2.9)$ & $0(0)$ \\
\hline $\begin{array}{l}\text { Different home prefecture from designated prefecture, } \\
\text { no. (\%) }\end{array}$ & $44(11.4)$ & $105(29.3)$ & $53(21.8)$ \\
\hline $\begin{array}{l}\text { Different medical school prefecture from designated } \\
\text { prefecture, no. (\%) }\end{array}$ & $11(2.8)$ & 104 (29.1) & $3(1.2)$ \\
\hline PGY-1 & $182(47.0)$ & $114(31.9)$ & $91(37.4)$ \\
\hline PGY-2 & $134(34.6)$ & $134(37.4)$ & $102(42.0)$ \\
\hline PGY-3 & $71(18.4)$ & $110(30.7)$ & $20(20.6)$ \\
\hline \multicolumn{4}{|l|}{ Outcome } \\
\hline Emigration to non-designated prefecture, no (\%) & $26(6.7)$ & $53(14.8)$ & $39(16.1)$ \\
\hline
\end{tabular}

Quota w/ scholarship: quota graduates with scholarship.

Scholarship alone: non-quota graduates with scholarship.

Quota alone: quota graduates without scholarship.

PGY, postgraduation year.

\section{Definitions of quota and scholarship}

A quota student is defined here as one whose 'geographic background or high school is restricted and/or whose postgraduate working place or specialty is clearly specified when admitted to a medical school'. ${ }^{12}$ A scholarship is 'given by a prefecture to a medical student which needs not to be paid back if the student works in areas designated by the prefecture for a certain period'. ${ }^{12}$ The participants of the study are thus divided into three groups: quota graduates with scholarship, non-quota graduates with scholarship (scholarship alone) and quota graduates without scholarship (quota alone).

\section{Measurement variables and evaluation process}

The main outcome was the emigration of regional quota graduates from the designated prefecture. We identified the designated prefecture from the questionnaire data and prefecture in which the subject actually works from the data in Physician Census 2016. We judged that the subjects emigrated if their designated prefecture and working prefecture were different.

The personal-level variables were age, gender, career length, graduation from a private medical school, length of scholarship, whether they admitted as a regional quota or not, whether home prefecture is identical with the prefecture where the graduated medical school is located, whether the designated prefecture is the same as prefecture where the medical school is located and permitted length of postponing obligation. In some prefectures, scholarship recipients have a right to postpone their obligatory service for a certain period; the longest postponement periods are different among prefectures. Prefecture-level variables were population density and whether the prefecture has an ordinance-designated city (seirei-shitei-toshi) or a special ward of Tokyo. Ordinance-designated cities $(n=20)$ are major cities, usually with a population of more than 500000 and are given a more administrative discretion by the national government than other cities.

\section{Statistical analyses}

We began by showing the individual-level and prefecture-level characteristics of each group of subjects: quota graduates with scholarship, scholarship alone and quota alone.

We conducted univariate analysis to examine the association between emigration and each of these characteristics. After confirming the non-normal distribution of participants in each variable, we used the Wilcoxon rank-sum test and $\chi^{2}$ test to compare emigrants and non-emigrants.

In addition, we examined the association between emigration and these characteristics by multilevel simultaneous logistic regression analysis after adjusting 


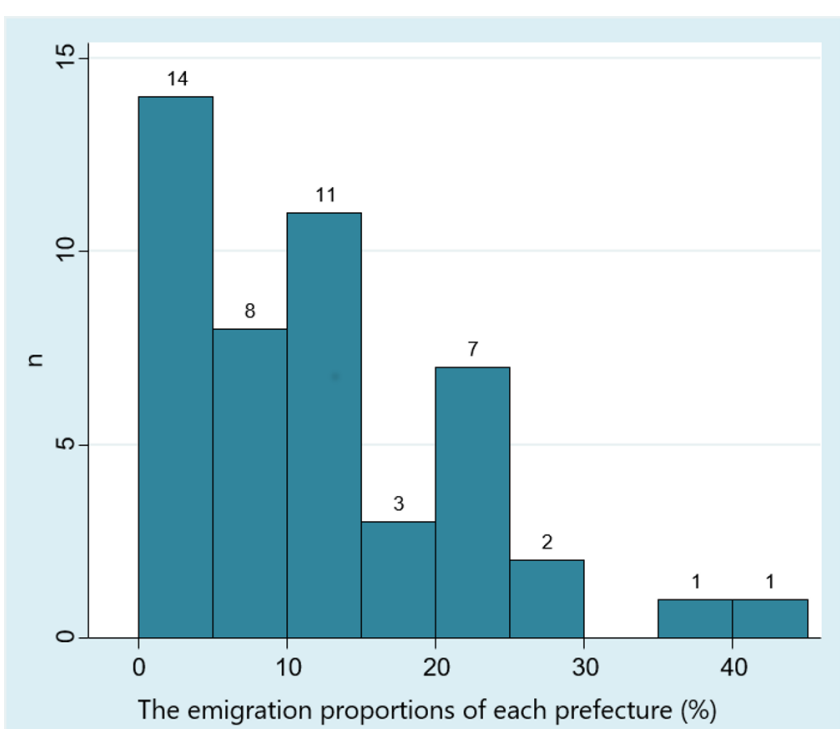

Figure 2 The proportion of emigrated cases among all participants at each prefecture.

for the individual-level and prefecture-level covariates. The individual-level covariates were age, gender, career length, graduation from a private medical school, admission as a quota, a scholarship, different home and designated prefectures, medical school outside of the designated prefecture, having a right to postpone obligatory service and length of duty period. The prefecture-level covariates were population density of the designated prefecture and the presence of an ordinance-designated city or Tokyo special ward. A multilevel mixed-effects model was adopted with a prefecture-level random effect to adjust for the effect of clustering of physicians with certain circumstances for each prefecture. The correlation among predictors was evaluated using variance inflation factors to assess multicollinearity. All statistical analyses were performed using STATA/SE V.14 (Stata, Texas, USA), and $\mathrm{p}<0.05$ was considered statistically significant,. ${ }^{19}$

\section{Patient and public involvement}

Subjects and the public were not involved in the design, recruitment and conduct of this study.

\section{RESULTS}

Between 2014 and 2016, all prefectures and medical schools completed the presurvey. Based on the 3 years of results, 129 prefectures and 70 medical schools had eligible subjects. Among them, 127 prefectures (98.4\%) and 70 medical schools $(100 \%)$ sent the questionnaire to potential subjects. The number of potential subjects of quota with scholarship 947, scholarship alone 1033 and quota alone was 727. Of these, $402(42.4 \%), 389$ $(37.7 \%)$ and $261(35.9 \%)$ responded, respectively. We excluded responders whose physician identification numbers were missing or could not be connected to those in Physician Census. Finally, 388 (41.0\%), 360
Table 2 Univariate analysis for association between individual or designated prefecture's characteristics and emigration

\begin{tabular}{|c|c|c|c|}
\hline & $\begin{array}{l}\text { Retained } \\
\text { physicians }\end{array}$ & $\begin{array}{l}\text { Emigrated } \\
\text { physicians }\end{array}$ & \multirow[b]{2}{*}{$P$ value } \\
\hline & $\mathrm{n}(\%)$ & n (\%) & \\
\hline \multicolumn{4}{|l|}{ Personal } \\
\hline $\begin{array}{l}\text { Age (median } \\
(\mathrm{IQR}))\end{array}$ & $26(25-27)$ & $27(26-28)$ & 0.005 * \\
\hline \multicolumn{4}{|l|}{ Gender } \\
\hline Male & $509(58.5)$ & $75(63.6)$ & \\
\hline Female & $361(41.5)$ & $43(36.4)$ & $0.30^{* *}$ \\
\hline $\begin{array}{l}\text { Career length } \\
\text { (median }(\mathrm{IQR}))\end{array}$ & $1(0-2)$ & $1(0-2)$ & $0.77^{*}$ \\
\hline \multicolumn{4}{|c|}{ Graduation from a private university } \\
\hline Yes & $110(11.5)$ & $16(13.6)$ & \\
\hline No & $770(88.5)$ & $102(86.4)$ & $0.43^{\star \star}$ \\
\hline \multicolumn{4}{|c|}{ Scholarship recipient } \\
\hline Yes & $666(76.6)$ & $79(66.9)$ & \\
\hline No & $204(23.4)$ & $39(33.1)$ & $0.02^{* \star}$ \\
\hline \multicolumn{4}{|c|}{ Admission as a quota } \\
\hline Yes & $565(64.9)$ & $65(55.1)$ & \\
\hline No & $305(35.1)$ & $53(44.9)$ & $0.04^{* *}$ \\
\hline \multicolumn{4}{|c|}{ Concordance between home and designated prefectures } \\
\hline Same & $702(80.7)$ & $84(71.2)$ & \\
\hline Different & $168(19.3)$ & $34(28.8)$ & $0.02^{\star \star}$ \\
\hline \multicolumn{4}{|c|}{$\begin{array}{l}\text { Concordance between medical school and designated } \\
\text { prefectures }\end{array}$} \\
\hline Same & $781(89.8)$ & $89(75.4)$ & \\
\hline Different & $89(10.2)$ & $29(24.6)$ & $<0.001^{\star *}$ \\
\hline \multicolumn{4}{|c|}{ Having a right to postpone obligatory service } \\
\hline Yes & $480(55.2)$ & $71(60.2)$ & \\
\hline No & $390(44.8)$ & $47(39.8)$ & $0.32^{\star \star}$ \\
\hline $\begin{array}{l}\text { Duty period } \\
\text { (median (IQR)) }\end{array}$ & $7(3-9)$ & $6(2-9)$ & 0.001 * \\
\hline
\end{tabular}

Regional (designated prefecture)

$\begin{array}{llll}\begin{array}{l}\text { Population } \\ \text { density of the }\end{array} & 0.19(0.14- & 0.19(0.13-0.3) & 0.64 \text { * } \\ \text { designated } \\ \text { prefecture }\end{array}$

Having an ordinance-designated city or special wards in the prefecture

\begin{tabular}{llll} 
Yes & $266(30.6)$ & $30(25.4)$ & \\
No & $604(69.4)$ & $88(74.6)$ & $0.25^{\star \star}$ \\
\hline
\end{tabular}

*Wilcoxon rank-sum test.

${ }^{\star \star} \mathrm{X}^{2}$ test.

$(34.9 \%)$ and $243(33.4 \%)$ were subject to analysis. ${ }^{11}$ Three physicians had missing values in key variables such as home prefecture information, leaving us with 988 physicians for analysis. 


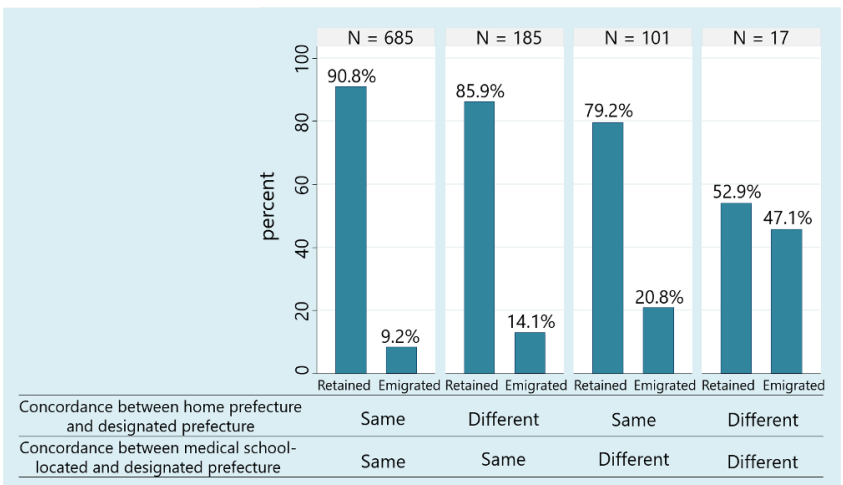

Figure 3 Proportion of emigrated cases classified according to concordance among home prefecture, medical school and designated prefectures. Emigrated, emigrated physicians; Retained, retained physicians.

Basic characteristics of subjects are shown in table 1 .

A total of 118 subjects emigrated from the designated prefecture, which means $11.9 \%(118 / 988)$ of the analysed participants. The number and proportion of emigrated participants in each group were as follows; $26(6.7 \%)$ quota graduates with scholarship, 53 (14.8\%) scholarship alone and 39 (16.1\%) quota alone.

Figure 2 shows the proportion of emigrated participants among all subjects at each prefecture. The mean (SD) number of emigrated cases was 2.5 \pm 2.8 among the prefectures. The mean (SD) proportion of emigrated participants was $11.7 \% \pm 10.3 \%$. The highest proportion was $44.4 \%$. Twelve prefectures had no emigration cases.

Results of univariate analysis for association between individual-level or prefecture-level characteristics and emigration are shown in table 2. Subjects who were older, who has a shorter duty period, who were not given scholarship, who were not admitted as a quota, whose home prefectures were different from designated prefectures and whose medical schools were located outside of designated prefectures were more likely to emigrate to non-designated prefectures. Population density of designated prefecture and existence of an ordinance-designated city within the prefecture were not associated with emigration.

Figure 3 shows the proportion of emigrated cases classified according to the concordance among the prefectures of medical school, birthplace and designation. When all the three prefectures were the same, only $9.2 \%$ of subjects emigrated. When all three prefectures were different from each other, the emigration proportion was $47.1 \%$.

Results of multilevel logistic regression analysis are shown in table 3. Recipients of a scholarship (OR 0.23; $95 \%$ CI 0.08 to 0.67 ) and whose designated prefecture had an ordinance-designated city (OR $0.47 ; 95 \%$ CI 0.24 to 0.90 ) were less likely to emigrate than the others. In contrast, those who graduated from a medical school outside the designated prefecture (OR 4.20; 95\% CI 2.20 to 8.02 ) and who can postpone the obligatory
Table 3 Individual and regional level variables that predict emigration of subjects from the designated prefectures

\begin{tabular}{|c|c|c|c|c|}
\hline \multirow[b]{2}{*}{ Covariates } & \multirow[b]{2}{*}{ OR } & \multirow[b]{2}{*}{$P$ value } & \multicolumn{2}{|c|}{$95 \% \mathrm{Cl}$} \\
\hline & & & Under & Upper \\
\hline \multicolumn{5}{|l|}{ Individual } \\
\hline Age (per year) & 1.00 & 0.95 & 0.95 & 1.06 \\
\hline Female & 0.86 & 0.48 & 0.56 & 1.32 \\
\hline Career length (per year) & 0.93 & 0.60 & 0.70 & 1.23 \\
\hline $\begin{array}{l}\text { Graduation from a } \\
\text { private medical school }\end{array}$ & 0.77 & 0.46 & 0.39 & 1.53 \\
\hline Scholarship recipient & 0.23 & 0.01 & 0.077 & 0.67 \\
\hline Admission as a quota & 0.76 & 0.37 & 0.41 & 1.39 \\
\hline $\begin{array}{l}\text { Different home } \\
\text { prefecture from } \\
\text { designated prefecture }\end{array}$ & 1.61 & 0.07 & 0.97 & 2.66 \\
\hline $\begin{array}{l}\text { Different medical } \\
\text { school prefecture from } \\
\text { designated prefecture }\end{array}$ & 4.20 & $<0.001$ & 2.20 & 7.67 \\
\hline $\begin{array}{l}\text { Having a right to } \\
\text { postpone obligatory } \\
\text { service }\end{array}$ & 3.42 & 0.003 & 1.52 & 7.67 \\
\hline Duty period (per year) & 0.92 & 0.07 & 0.83 & 1.01 \\
\hline \multicolumn{5}{|l|}{ Regional } \\
\hline $\begin{array}{l}\text { Population density of } \\
\text { prefecture }\left(1000 / \mathrm{km}^{2}\right)\end{array}$ & 1.00 & 0.46 & 0.99 & 1.00 \\
\hline $\begin{array}{l}\text { Prefectures with an } \\
\text { ordinance-designated } \\
\text { city }\end{array}$ & 0.47 & 0.02 & 0.24 & 0.90 \\
\hline
\end{tabular}

service (OR 3.42; 95\% CI 1.52 to 7.67 ) were more likely to emigrate than the others.

\section{DISCUSSION}

The results of this study revealed that $11.9 \%$ of regional quota graduates and prefecture scholarship recipients emigrated from the prefecture in which they were obliged or expected to work. Several personal or regional characteristics, such as gradation from a medical school outside the designated prefecture and designated prefecture without an ordinance-designated city, predicted future emigration of them.

Emigration has become a grave social problem in Japan as the number of graduates of regional quota is expanding rapidly. ${ }^{16}$ But emigration itself is not necessarily the same as medical school graduates' violation of their service obligation. As shown in the results, over half of the graduates have a right to postpone the obligatory service. Although those who can postpone their service were more likely to emigrate, they potentially are still under the scholarship contract and may eventually return to their obligatory service in the designated prefectures. However, considering the mission of regional quota and prefecture scholarship, the number of such emigrations should be reduced. ${ }^{12} 20$ 
Being the recipient of a prefecture scholarship was a negative predictor for emigration but admission to a quota was not a significant predictor. This means scholarship has a larger influence than quota admission on retention of the physicians in the designated prefectures. This is an expected result because the obligation of quota without scholarship (quota alone) is not really an obligation but an expectation. Unlike scholarship recipients, quota students without scholarship do not have a legal responsibility to work in the designated prefecture although they had been permitted to admit to a medical school on condition that they would. Based on the results, we cannot avoid concluding that quota without scholarship, as a policy for retaining rural physician workforce, has room for improvement.

Our study showed that the concordance among birthplace, medical school and designated prefectures has an additive effect each other on retention. Even though each medical school location and home prefecture has its own effect on emigration, multivariate analysis showed that having a different birthplace from the designated prefecture was not a significant predictor for emigration. In contrast, a medical school outside the designated prefecture was a significant predictor (OR 4.19). Although past studies showed the correlation between the rural origin and their work place, we detected the location of medical school as a stronger factor than home prefecture to retain the subjects in the designated places. ${ }^{3}$ In 2017, the Ministry of Health, Labour and Welfare announced that the scholarship for regional quota entrants cannot be budgeted from the national government's Fund for Comprehensively Securing Regional Health and Long-term Care unless the entrant's home prefecture was the same as the designated prefecture. The government explained that this policy would increase retention rate of the graduates in the designated prefecture. However, the results of this study revealed that the concordance between the location of medical school and the designated prefecture was more important than the concordance between the birthplace and the designated prefecture. Ideally, the student's birthplace, medical school and designated prefectures should be the same. This would maximise the retention of scholarship recipients within the target area.

Prefectures with an ordinance-designated city were more successful in retaining quota graduates and scholarship recipients than prefectures without one. Prefectures with a large city would be advantageous for retaining them because they offer more opportunities for within-prefecture specialty training and urban life. Quota graduates and scholarship recipients are obliged to work in prefectures for a certain period, part of which should be dedicated to rural practice. This means the rest of the obligatory periods can be spent, if the graduate wishes, in a large city in such prefectures. This would attract more physicians to prefectures with a large city.

Several countries have programmes that are, to some extent, similar to the Japanese regional quota and prefecture scholarship. Medical school admission quotas such as the Physician Shortage Area Program of Thomas Jefferson University in the USA and the Rural Area Project of Chulalongkorn University in Thailand have been created specifically to produce rural physicians,. ${ }^{21}{ }^{22}$ There are also entire medical schools that have been created with a mission to train and graduate rural physicians, such as Northern Ontario School of Medicine in Canada and Ateneo de Zamboanga University School of Medicine in the Philippines. ${ }^{23} 24$ These quotas or schools can potentially be more effective if they are combined with scholarships provided by local governments. Many countries have incentives such as medical school scholarships in exchange for a period of rural service; one example is the National Health Service Corps in the USA. ${ }^{25}{ }^{26}$ As the results of this study suggest, the concordance among birthplace, medical school and designated places may improve the retention rates of these financial incentive programmes.

This study has several limitations. First, the 3-year follow-up period of this study is insufficient to assess the long-term effectiveness of regional quota and prefecture scholarship programmes. Second, the response rate of potential subjects was not $100 \%$. If the subject selection is biased, their geographic distribution would be different from the distribution of all potential subjects. However, we sent the questionnaire to almost all quota graduates and scholarship recipients in Japan. Also the response rate of each prefecture was not significantly correlated with its population density (Spearman's correlation coefficient $0.132, \mathrm{p}=0.378)$. We thus consider that the selection bias should be minimal. Third, the emigration cases in this study include those in 'excusable circumstances', such as those who legally postpone the obligatory service to take a specialty training in other prefectures because the designated prefecture did not offer it. Last, we could not show the quality of services that might be affected by the obligatory nature of quota and scholarship programmes. Future studies should focus on the issue of service quality, graduates who bought out their scholarship to avoid the in-prefecture service and analyse factors associated with that behaviour.

As the regional quota is based on temporary national legislation, the programmes will undergo substantial revision from 2020. A special committee of the Ministry of Health, Labour and Welfare for supply of healthcare professionals is now discussing the desirable size and design of the future quota programmes. Results of this study would lay the scientific groundwork for the better-designed quota programmes. In these new subquota programmes, scholarship should be 100\% bundled, and recruited students' home, medical school and designated prefectures should ideally be the same.

\section{CONCLUSION}

For some personal and regional reasons, a substantial proportion of regional quota graduates and prefecture scholarship recipients have emigrated to prefectures 
where they were not obliged or expected to work. Based on these results, the national government should undertake the immediate revision of these policies.

\section{Author affiliations}

${ }^{1}$ Department of Community-Based Medical System, Graduate School of Biomedical and Health Sciences, Hiroshima University, Hiroshima, Japan

${ }^{2}$ Environmental Health Sciences Laboratory, Department of Development Technology, Graduate School for International Development and Cooperation, Hiroshima University, Higashi-Hiroshima, Japan

${ }^{3}$ Education Center for Doctors in Remote Islands and Rural Areas, Graduate School of Medical Sciences, Kagoshima University, Kagoshima, Japan

${ }^{4}$ Department of Community Medicine, Niigata University Graduate School of Medical and Dental Sciences, Niigata, Japan

${ }^{5}$ Department of Community Medicine, Chiba Medical Center, Teikyo University School of Medicine, Chiba, Japan

${ }^{6}$ Department of General Internal Medicine, Hiroshima University Hospital and Graduate School of Biomedical and Health Sciences, Hiroshima, Japan ${ }^{7}$ Department of Island Community Medicine, Nagasaki University Graduate School of Biomedical Science, Nagasaki, Japan

Contributors SY contributed to analysis and interpretation of data and writing of the draft. MM contributed to the study design, tools, study administration, data collection, analysis and interpretation of data and writing of the draft. TM contributed to the study design, tools, study administration and writing of the draft. SK contributed to the data analysis, data interpretation and writing of the draft. KI, TO, SI and ST contributed to the study design, data collection and writing of the draft.

Funding This study is funded by the Ministry of Education, Culture, Sports, Science and Technology KAKENHI Grant-in-Aid for Scientific Research (C), grant number (18K10084) and by the Satake Fund. This study was also funded by the Pfizer Health Research Foundation.

Competing interests None declared.

Patient consent for publication Not required.

Ethics approval Ethical approval was granted by the Ethics Committee for Epidemiological Research of Hiroshima University (reference number 778) and the Research Ethics Committee of Nagasaki University Graduate School of Biomedical Sciences (reference number 13091342).

Provenance and peer review Not commissioned; externally peer reviewed.

Data sharing statement The titles of all relevant data sets in this study are described in the manuscript. Conditions of the ethical approvals permit the cohort office (Department of Community-Based Medical System, Institute of Biomedical and Health Sciences, Hiroshima University) and the sub office (Department of Community Medicine, Nagasaki University Graduate School of Biomedical Science) to share the original cohort data. Aggregated data are shared with stakeholders or other researchers. The data from the Survey of Physicians, Dentists and Pharmacists are third party data and are available from the Ministry of Health, Labour and Welfare (http://www.mhlw.go.jp/toukei/sonota/chousahyo.html) for researchers whose study purposes and methodologies meet its criteria fo raccess to confidential data. The Ministry prohibits the researchers to open the data set to any other individual or party.

Open access This is an open access article distributed in accordance with the Creative Commons Attribution Non Commercial (CC BY-NC 4.0) license, which permits others to distribute, remix, adapt, build upon this work non-commercially, and license their derivative works on different terms, provided the original work is properly cited, appropriate credit is given, any changes made indicated, and the use is non-commercial. See: http://creativecommons.org/licenses/by-nc/4.0/.

\section{REFERENCES}

1. Makaroff LA, Green LA, Petterson SM, et al. Trends in physician supply and population growth. American family physician 2013;87. Online.
2. Ono T, Schoenstein M, Buchan J. Geographic Imbalances in Doctor Supply and Policy Responses, 2014.

3. Organization WH. Increasing access to health workers in remote and rural areas through improved retention: global policy recommendations, 2010.

4. Rabinowitz HK, Paynter NP. The role of the medical school in rural graduate medical education: pipeline or control valve? J Rural Health 2000;16:249-53.

5. Greenhill JA, Walker J, Playford D. Outcomes of Australian rural clinical schools: a decade of success building the rural medical workforce through the education and training continuum. Rural Remote Health 2015;15:2991.

6. Frehywot S, Mullan F, Payne PW, et al. Compulsory service programmes for recruiting health workers in remote and rural areas: do they work? Bull World Health Organ 2010;88:364-70.

7. Kobayashi $\mathrm{Y}$, Takaki H. Geographic distribution of physicians in Japan. The Lancet 1992;340:1391-3.

8. Matsumoto M, Inoue K, Kajii E, et al. Retention of physicians in rural Japan: concerted efforts of the government, prefectures, municipalities and medical schools. Rural Remote Health 2010;10:1432

9. Matsumoto M, Inoue K, Bowman R, et al. Geographical distributions of physicians in Japan and US: Impact of healthcare system on physician dispersal pattern. Health Policy 2010;96:255-61.

10. Hara K, Otsubo T, Kunisawa S, et al. Examining sufficiency and equity in the geographic distribution of physicians in Japan: a longitudinal study. BMJ Open 2017;7:e013922.

11. Toyabe S. Trend in geographic distribution of physicians in Japan. Int $J$ Equity Health 2009;8:5.

12. Matsumoto M, Takeuchi K, Owaki T, et al. Results of physician licence examination and scholarship contract compliance by the graduates of regional quotas in Japanese medical schools: a nationwide cross-sectional survey. BMJ Open 2017;7:e019418.

13. Matsumoto M, Inoue K, Takeuchi K. Quality of care in Japan: an additional strategy. The Lancet 2011;378:e17.

14. Matsumoto M, Takeuchi K, Tanaka J, et al. Follow-up study of the regional quota system of Japanese medical schools and prefecture scholarship programmes: a study protocol. BMJ Open 2016;6:e011165.

15. Matsumoto M, Kashima S, Owaki T, et al. Geographic distribution of regional quota program graduates of japanese medical schools: A nationwide cohort study. Acad Med. In Press. 2019:1.

16. Arata Matsuura SE. Faculty of medicine regional quota expansion conditions are working in the area. But Outside the Prefecture Outflow. The Asahi Shimbun Digital 2018.

17. Sen Gupta T, Woolley T, Murray R, et al. Positive impacts on rural and regional workforce from the first seven cohorts of James Cook University medical graduates. Rural and remote health 2014;14:2657.

18. Matsumoto M, Inoue K, Kajii E. Policy implications of a financial incentive programme to retain a physician workforce in underserved Japanese rural areas. Soc Sci Med 2010;71:667-71.

19. StataCorp. 2015. Stata Statistical Software: Release 14. College Station. TX: StataCorp LP. [program], 2015.

20. Colleges. AoJM. Heisei 28 nendo chiikiwaku-nyugaku-seido to chiikiiryo-shien-senta no jitsujou ni kansuru chousahoukoku (Survey report on regional subquota admission and community health support centers in 2016). Tokyo: AJMC 2017;2017.

21. Rabinowitz HK. Evaluation of a selective medical school admissions policy to increase the number of family physicians in rural and underserved areas. N Engl J Med 1988;319:480-6.

22. Sriratanaban A, Sangprasert B. The Rural Area Project (RAP) in Thailand: curriculum development. Med Educ 1983;17:374-7.

23. Cristobal F, Worley P. Can medical education in poor rural areas be cost-effective and sustainable: the case of the Ateneo de Zamboanga University School of Medicine. Rural Remote Health 2012;12:12

24. Hogenbirk JC, French MG, Timony PE, et al. Outcomes of the Northern Ontario School of Medicine's distributed medical education programmes: protocol for a longitudinal comparative multicohort study. BMJ Open 2015;5:e008246.

25. Garcia AN, Kuo T, Arangua L, et al. Factors Associated With Medical School Graduates' Intention to Work With Underserved Populations: Policy Implications for Advancing Workforce Diversity. Academic medicine: journal of the Association of American Medical Colleges 2018:93:82-9.

26. Bärnighausen T, Bloom DE. Financial incentives for return of service in underserved areas: a systematic review. BMC Health Serv Res 2009;9:86. 